\section{ON THE CONSTRUCTION OF A NEW GLYCERINE BAROMETER}

$T \mathrm{HE}$ direct influence of changes of atmospheric pressure on the occurrence of many of our colliery accidents, so clearly diemonstrated by the investigations of Messrs. Scott and Galloway, has naturally led to the consideration of barometers affording a wide range of movement, thereby rendering small atmospheric changes at once apparent, and clearly noticeable to the uneducated eyes of those engaged in such situations as collieries, storm stations, and other places where it is important to note rapid movements without the careful observation which is requisite for the correct reading of an ordinary mercurial barometer.

Among the various attempts which have been made from time to time to construct long range barometers, may be mentioned the celebrated water barometer, constructed at great cost for the Royal Society in 1830 , by Prof. Daniel, but a water column is found to be unreliable in its action, the effects of pressure being so often masked by variations due to changes of temperature on the aqueous vapour existing in the Torricellian vacuum. Mr. Jas. B. Jordan, of the Mining Record Office, has for some years been devoting much attention to this subject, believing that if precise instruments of this class could be made, they would prove of scientific value in showing the character of the more minute vibrations of pressure, and of practical use for the purpose above referred to. The fluid which has shown the most successful results appears to be glycerine-and a glycerine barometer was constructed by Mr. Jordan in the year 1870 , which is still in operation. The purest glycerine, as manufactured by Messrs. Price and Co., has a specific gravity of $1 \cdot 26$; from its high boiling-point, $440^{\circ} \mathrm{Fah}$, it has a very low tension of vapour at the ordinary temperatures of the atmosphere, and a very low temperature is required to freeze it. The mean height of a column of glycerine is 27 feet, and a variation of one-tenth of an inch, in the height of a mercurial column is shown by a change of more than an inch in the glycerine column. The glycerine absorbs moisture freely when exposed to the atmosphere, but this is prevented by covering the exposed surface of the liquid in the cistern with a layer of heavy petroleum oil prepared especially for the purpose. Barometers of this character have also been constructed by $\mathrm{Mr}$. Jordan at the South Kensington and Jermyn Street Museums with good results. Still further to test the scientific value of the new instrument, application was made to the Government Grant Committe of the Royal Society for a small grant of money to construct an experimental barometer, and an instrument was erected therewith at the Kew Observatory, by the permission of the Kew Committee.

A detailed description of the instrument has recently been read at the Royal Society by the inventor. The accompanying figure explains its construction: the cistern is a cylindrical vessel of copper tinned inside, 5 inches deep and ro inches diameter, fitted with a screwed cover, $B$; the air having access through a small hole in the cap, $\mathrm{C}$, attached to the cover, which has a recess, holding cotton wool for filtering out the dust. The main tube is connected with the cistern by attachment (with a soldered joint) to a projecting piece of tube $D$, which enters the cistern through the bottom, and is fitted at its opening with a screwed plug, E. The tube is an ordinary composition metal gas-pipe, five-eighths of an inch in diameter, furnished at the top with a gun-metal socket, into which is cemented a glass tube 4 feet in length, with an inside diameter of $I$ inch, terminating in an open cup, and fitted with an india rubber stopper.

The fluctuations of the level of the column of glycerine are observed and read off on brass scales placed on either side of the tube, fitted with indices and verniers, moved by milled heads, A A, at the bottom of the scales. The right-hand scale gives inches and tenths of absolute measure from the level of the liquid in the cistern; the left-hand scale the equivalent value in a column of mercury, divided into tenths and hundredths, the hundredth division being equal to about one-tenth of an actual inch.

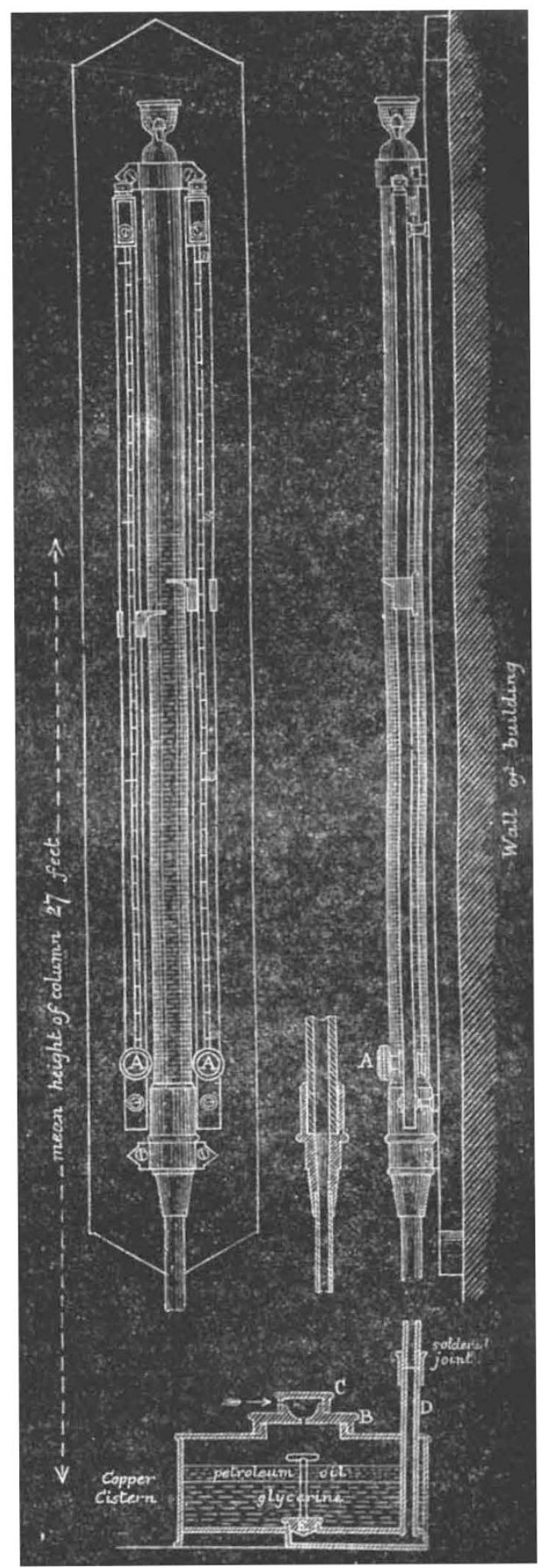

The observing part of the barometer is attached to an oak back fixed to the wall of an upper room in the Observatory, the main tube being carried down through the entrance hall to the barograph room below. a distance of $27 \mathrm{feet}$, where the cistern is placed on a bracket on the 
north wall, the distance being accurately measured with a tape, the error of which was found by comparison with the standard yard preserved in the Observatory.

The cistern was filled with three-fourths of a gallon of glycerine, coloured red by aniline, first heated to a temperature of $100^{\circ} \mathrm{F}$. to render it more limpid, so as to disengage the air more freely; the plug, E, was then removed, and the air extracted out of the tube by means of an air pump connected at the top of the glass tube, when the pressure of the atmosphere forced the liquid up to a height of 323.57 I inches, being equivalent to 30 inches of mercury, the Kew standard at the time reading $30^{\prime} 3$ inches. The plug was then screwed in to support the column, air admitted at the top, the air-pump connections removed, and the tube filled up to the top with glycerine, and the india-rubber stopper inserted. The screw plug being removed for a few seconds to allow the column to fall an inch or two, was then replaced, and the instrument left, until the liquid was completely exhausted of air, which slowly rose to the surface, into the vacuum above the india-rubber stopper was again withdrawn, the tube filled up, the stopper replaced, and the cistern plug finally removed, when the column gradually fell until balanced by the weight of the atmosphere, leaving a small quantity of glycerine in the cup above the stopper, over which a plate-glass cover was placed to keep out the dust.

Daily observations of this instrument are now being regularly taken at Kew Observatory, under the superintendence of Mr. Whipple, the Director, which will decisively prove whether the instrument is to be regarded as one of scientific precision, but in any case the inventor is to be congratulated on having reduced to a simple construction an instrument forming a large scale weather-glass, suitable for ordinary observation, which cannot fail to be of interest and value at our museums and other public institutions.

C. F. R.

\section{THE HISTORY OF WRITING ${ }^{1}$}

I HAVE promised to speak to you to-night on a large 1 subject, one which, to be treated adequately, would require, not a single lecture or a single hour, but many lectures and many days. The history of writing is in great measure the history of the human mind; just as anything like real abstract thought is impossible without language of some kind, so, too, without writing it is diffcult to conceive of a progressive civilisation or a developed culture. The trained memory is no doubt able to accomplish marvellous feats, as we may learn from the Hindus, who have preserved by means of it, through long centuries, not only poems, but even scientific works as well; nevertheless, the memory has a limit, and I think most of us would be sorry to trust to it alone for the record of our own thoughts and discoveries, much less those of others. If language gave man the power of continuous thought, writing has enabled him to develop and make use of it.

There is a striking analogy between the history of language and the history of writing. Both have sprung from a humble origin. Language began with a few sounds and cries which symbolised and expressed an equally small number of ideas; writing began with pictures of such objects as fell within the experience of the first draughtsmen. How early this was in the history of our race has recently been disclosed to us by archæological research. Like the child, primitive man amused himself by drawing pictures of the things he saw about him, and like precocious children sometimes showed remarkable talent in practising the art. The drawings of reindeer and other animals, scratched by means of rude flint implements on reindeer-horns or mammoth-tusks, which have been found in the caves of France and our own country, are frequently of high merit, and prove that

I Lecture at the London Institution, February 12, by Prof. A. H. Sayce. considerable skill in the art of drawing may coexist with the lowest savagery in other respects. It is a lesson that we might already have learnt from the Eskimo, whose etchings on whalebone are not unworthy of European artists, or from the Bushmen of Southern Africa, who have long excelled in painting animal forms on the smooth surfaces of rocks. But these contemporaries of the reindeer and the mammoth, who belonged to what is termed the age of polished stone tools, when England and France were still enfolded for six months of the year in a garment of glaciers and solid ice, were not the first in the West who practised the art of drawing. A remarkable discovery, made during the past year in the region of the Pyrenees, has shown that long before then, in the days when the cave-bear and hyæna and other extinct monsters of the old world still existed, and when the geography of Europe differed widely from that of our own time, there were men who employed their leisure in depicting the animals about them as well as themselves. A number of teeth belonging to the cave-bear have been discovered in a cave of the palæolithic or "old-stone" period, adorned with drawings, some of which represent human beings, covered, let it be observed, with long hair like the mammoth. I have sometimes fancied that language itself may have owed its first start and progress to pictorial aid. It is said that two Chinamen, in despair of understanding each other through the help of a language which has to denote so many different ideas by the same sound, have been known to have recourse to writing; and most of us remember when our own efforts to learn to read, and in some cases to incrcase our acquaintance with our mothertongue, were assisted by the use of pictures. An appeal to the eye is surer and more impressive than an appeal to the ear, and we recognise objects more readily by their pictures than by their names. After all, therefore, it may not be a paradox to imagine that the beginnings of writing may be older than the beginnings of language, that men drew pictures before they uttered articulate sounds.

However this may be, the development of writing was soon far outstripped by that of language. Language enabled man to create and record ideas; the pictures he made were pictures of objects only. Until he could represent to the eye ideas as well as objects, his writing was a very poor affair indeed. It is only by courtesy that it can be called writing at all. But a time came when a great step forward was made. The ideas that had to be supplied when combining the pictures of several objects into a story gradually came to be read into the pictures themselves. A pair of legs, for instance, came to signify not only a man's legs but the idea of walking as well. Writing began to pass out of its infantile stage; to cease to be merely pictorial and to become ideographic.

This is the point at which the development of writing has stopped among some races of men. Thus certain of the North American Indians have long possessed a means of communicating with one another, and of inscribing magical charms and exorcisms on rocks or the bark of trees, by means of pictures and ideographs. When these hieroglyphs, as we may term them, are painted, the system of writing is called Kekinowin, and some of the pictorial symbols employed in it are curious enough. A warrior, for example, is represented by the picture of the sun, with eyes, and nose, and two pendant lines, because he ought to be as bold and strong as the great luminary of day. $A$ hand held upwards with the fingers extended denotes death, and a series of circles one within the other signifies time. This system of writing has been developed to such an extent among the Mikmaks, that a religious work has been published at Vienna entirely written in it, and containing no less than 5,70r different signs.

As soon as writing advances to the ideographic stage, the exact delineation of outward objects naturally ceases to be necessary. When once it has been determined that 